\title{
Narrativas publicitarias de la modernidad en la prensa colombiana de los años treinta
}

\author{
Advertising narratives of \\ modernity in the Colombian \\ press of the thirties
}

\author{
Mirla Villadiego Prins (Colombia) \\ mvilla@javeriana.edu.co \\ Pontificia Universidad Javeriana

\section{Patricia Bernal Maz (Colombia) \\ pbernal@javerian.edu.co \\ Pontificia Universidad Javeriana}

\author{
María Urbanczyk (Rusia) \\ murbanczyk@javeriana.edu.co \\ Pontificia Universidad Javeriana
}

\section{Resumen \\ Este artículo presenta algunos resultados de la investigación La modernidad colombiana contada por el relato publicitario: 1900-1950. La exposición se concentra en la década de los años treinta y da cuenta de la construcción narrativa que la publicidad hizo de la modernidad en Colombia, a partir del análisis estructural de Barthes,}

\begin{abstract}
This article presents some results of the research: Colombian modernity told by the advertising narration: 1900-1950. The exhibition focuses on the decade of the thirties and accounts for the narrative construction that advertising story telling made of modernity in Colombia, from a structural analysis of Barthes, but without losing sight of the reference to the
\end{abstract}

Para citar este artículo / to cite this article

Bernal, P; Villadiego, M. \& Urbanczyk, M. (2013).

Narrativas publicitarias de la modernidad en la

prensa colombiana de los años treinta. Poliantea IX, (16), pp. $211-239$ 
pero sin perder de vista la referencia a los contextos desde los cuales esa publicidad era recibida por los lectores de los periódicos. Esta manera de proceder permitió entender no solo qué pudo significar en el país ser o sentirse modernos, sino también comprender las lógicas desde las cuales la narración publicitaria se producía para hacer familiar entre sus consumidores, reales o potenciales, una nueva época, la época moderna, que para ese entonces se traducía en una novedad desconocida para la mayoría de los colombianos.

Palabras clave: denotación, connotación, narración, modernidad, publicidad. context from which the advertising was received by the newspapers readers. This approach helped to understand not just what it might mean to be or feel modern, but also to understand the logics from which the advertising narrative was produced to become familiar among its actual or potential consumers. It was a new era, the modern era, which by then was was regarded as an unknown novelty to most Colombians.

Keywords: denotation, connotation, narrative, modernity, advertising. 


\section{Narrativas publicitarias de la modernidad en la prensa colombiana de los años treinta}

Mirla Villadiego Prins (Colombia)

Máster en Comunicación

Patricia Bernal Maz (Colombia)

Doctora en Filosofía

María Urbanczyk (Rusia)

Máster en Comunicación

\section{Introducción}

Este artículo está dedicado a examinar la narrativa publicitaria de la modernidad en la prensa colombiana de la década de los años treinta. Para los propósitos de este artículo, se entenderá por narrativa "la representación de eventos y situaciones, reales o ficticias en forma de secuencia" (Reyes, 2003, p. 97). Esta es una definición clásica de las narrativas, las cuales se constituyen a partir de un llamado de atención sobre "la desviación de una norma, una expectativa o una costumbre" (Contursi y Ferro, 2000, p. 30), que al constituirse como el núcleo de lo narrado se convierte en el eje de la complicación que hace atractiva la historia. Sin embargo, la narración no se agota en esta situación problemática, pues, como bien lo ha planteado Jean Michel Adam en la narración es posible identificar una situación inicial, una complicación, una reacción, una resolución y una situación final, que bien podría invitar a una reflexión a la manera de moraleja (citado por Contursi y Ferro, 2000, p. 27).

Más allá de las definiciones clásicas de la narración, las narrativas publicitarias de la década de los treinta exponen una historia en la que, por lo general, no hay transgresión de la norma sino problemas cotidianos que para ser resueltos demandan del consumo de productos, servicios y marcas que ofrecen los anunciantes. No obstante, una sociedad tradicional, como la 
colombiana, hizo necesario, además, ubicar a esos productos, servicios y marcas en el contexto de la transición entre tradición y modernidad, para lograr hacer comunicable y significativo no solamente la práctica de consumo, más allá de la supervivencia, sino también el nacimiento de una nueva época a la que había que adaptarse en la medida en que resultaba conveniente para los intereses de los empresarios colombianos, pero también de los inversionistas extranjeros que llegaban al país.

La narración publicitaria constituyó una lógica que se estructuró de tal manera que llevó a cabo operaciones complejas en las que, por una parte, se hablaba al consumidor desde mentalidades todavía instaladas en el mundo tradicional, muy posiblemente para establecer con ellos vínculos de familiaridad, y por otra, también se deslegitimaba a ese mundo tradicional, con una crítica implícita en la misma narración.

Descubrir esta lógica de narración implicó para la investigación someter alrededor de 350 anuncios publicitarios a un riguroso escrutinio para conocer su estructura desde dos dimensiones: una dimensión denotativa, que aborda lo dicho explícitamente en los anuncios publicitarios, y una dimensión connotativa, que de acuerdo con Barthes estudia "lo no dicho pero plenamente significativo" en dichos anuncios. Ambas dimensiones se complementan para dar cuenta de las relaciones existentes entre publicidad y modernidad, tanto desde la perspectiva histórica como epistemológica y metodológica.

\section{Dimensión denotativa}

El estudio de la dimensión denotativa de los anuncios comprendió su examen desde el punto de vista de las formas expresivas de los anuncios, o lo que se llama la estética del anuncio; el análisis de las estructuras de sus contenidos, o lo que se llama fórmulas narrativas del relato publicitario, y el análisis a los contenidos mismos de los anuncios, ya fuera para examinar los temas de los anuncios, los personajes, los productos anunciados y sus atributos modernos, los procesos de modernización referenciados o las nociones de espacios y tiempos.

\section{La estética del anuncio}

Por lo general, los anuncios de la década de los años treinta estaban compuestos por un título, un copy y una ilustración. En algunas 
oportunidades, los anuncios incluían un cupón que el consumidor podía recortar para reclamar al anunciante un obsequio.

El color y la fotografía eran casi inexistentes para las publicaciones diarias, mientras que las ilustraciones eran una constante. Sin embargo, en el caso de las revistas semanales, la situación era inversamente proporcional, puesto que en ellas lo persistente eran las fotografías y el color. A menudo, las ilustraciones presentaban el anuncio dentro de una viñeta que funcionaba como marco de lo que, por lo general, bien podía ser considerado como una verdadera obra de arte.

La tendencia estética dominante en los anuncios publicados al comenzar el siglo XX estaba condicionada por las posibilidades expresivas de las tecnologías de comunicación disponibles en ese momento, por lo tanto, los anuncios publicitarios respondían inevitablemente al uso de la tipografía. El tipo de letra que caracteriza los avisos era un tipo de letra legible y claro en muchos casos; en otros se hacía uso de la caligrafía para destacar el uso o el nombre del producto. El tipo de letra que predominaba era la serifada (hoy, Times New Roman).
El surgimiento del cartelismo en la Primera Guerra Mundial marcaría la tendencia estética de los años treinta. En esta década, se dejaba atrás la que hasta entonces era la tendencia dominante, que se caracterizaba por lo lineal y lo simple. Durante estos años, por el contrario, se produjo un desborde artístico que se vio reflejado en la pieza publicitaria, donde las líneas se hacían más sinuosas, sueltas y armoniosas, para propiciar el recorrido visual del anuncio.

Los textos eran reforzados por una ilustración expresionista y detallada, adornada con grafismos propios del Art Nouveau que resaltaban y enmarcaban el dibujo dándole total importancia. La ilustración no solo hacía referencia al producto o la marca, sino que era una representación de una realidad que no necesariamente pertenecía al diario vivir de comienzos de esta década en Colombia, sino a situaciones propias de los países desarrollados de donde procedían muchas de las mercancías anunciadas por la publicidad.

El concepto de arte hasta el momento conocido, los valores estéticos, sociales y culturales cambiaron cuando se introdujo la técnica de la litografía en la representación 
artística y se establecieron nuevos parámetros en el arte de la época moderna. Probablemente, por eso, fueron los artistas quienes se encargaron de la tarea de ilustrar los anuncios publicitarios y convertirse en los primeros diseñadores gráficos de la primera mitad del siglo XX.

En este momento se introdujo el uso del color basado en una sola tinta en los anuncios de prensa y a tres tintas en los de las revistas especializadas, lo mismo sucedía con el uso de la tipografía, el manejo de las ilustraciones y la introducción de la fotografía. Las revistas especializadas manejaban una estética más libre y menos ajustada a los parámetros estéticos de la prensa.

Las ilustraciones tanto para revista como para prensa manejaban la misma simbolización y comunicación; eran hermosamente adornadas y trabajadas dando cuenta de un estilo de vida importado, pues, los personajes que en ellas se ilustraban representaban estilos de vida de hombres y mujeres bastante estilizados que, en principio, no respondían a un tipo de cultura latina.

\section{Las fórmulas narrativas de los anuncios}

Las estructuras narrativas de los relatos publicitarios se organizaban bajo tres fórmulas básicas desde las cuales se presentaban los productos a los consumidores con distintos niveles de complejidad. En la fórmula más elemental del relato, el anuncio simplemente presentaba el producto, con el precio, el nombre del distribuidor, el lugar de la venta $y$, algunas veces, el nombre de la marca. En la segunda de esas fórmulas, se expone un problema y a renglón seguido su solución, desde luego asociada con el consumo del producto o la marca, y finalmente, en la tercera fórmula, se introducía el producto, sustentando con argumentos sus cualidades y los beneficios que representaban esas cualidades para el consumidor.

Llama la atención que la fórmula narrativa más recurrente fuera la que presentaba a los productos, desde su capacidad para solucionar una serie de problemas que para el consumidor podían resultar cotidianos, como aquellos relacionados con la enfermedad, la educación y la operatividad técnica de los aparatos. Igualmente, llama la atención que esos anuncios presentaran al producto 
desde su posibilidad de otorgar beneficios para el consumidor, por ejemplo la estimación social, el ahorro del esfuerzo, del tiempo y del dinero, así como la manera de ir al compás de los nuevos tiempos, a través del consumo de los productos.

La fórmula narrativa supone también el establecimiento de vínculos con el consumidor; esto se logra a través de la construcción de unos personajes que lo representan, porque comparten las situaciones que este vive, que le enseñan, porque le cuentan o le explican algo que ese consumidor desconoce. Adicionalmente, la fórmula narrativa también se vale de un narrador indiferenciado que llama la atención del consumidor para contarle los beneficios del producto e invitarlo a conocerlo y a consumirlo.

A este respecto y teniendo en cuenta los resultados arrojados por la investigación, se observa que de manera predominante los anuncios se valen de personajes que representan al consumidor y de narradores indiferenciados que, en una menor proporción, le enseñan algo a través de los testimonios, en los que explícitamente se declara la satisfacción con las bondades de los productos o servicios anunciados.

\section{Los temas de los anuncios}

Concretamente, se observa que, antes de la década los treinta, el relato publicitario de productos $y$ servicios era dirigido a una reducida élite con poder adquisitivo; ello explica que no existiera la preocupación por presentar a esos productos como la solución a problemas de reconocimiento social o como la solución de problemas técnicos, económicos o políticos. Previo a estos años treinta, los productos eran anunciados como un asunto de lujo de una minoría y no como un tema que podía ser concerniente a una más amplia capa de población, con necesidades de conocer en detalle lo que se anunciaba, pero también con la necesidad de hacerse reconocer, socialmente, a través del consumo. Lo que había en el país era, sin duda alguna, una muy desigual distribución de la riqueza y del ingreso, que redundaba en el bajo poder adquisitivo de la mayor parte de la población y un acceso restringido a las publicaciones en las que estos anuncios circulaban; pero esto no era contado por el relato publicitario.

Contrastando este panorama, a partir de 1930 se empieza a evidenciar un cambio en el relato publicitario, 
en el cual hay una apertura que permite tematizar las bondades de los productos y su ubicación en un contexto (moderno) desconocido para una buena parte de los nuevos destinatarios de este relato publicitario, e igualmente se hace evidente en esos relatos la necesidad de dar paso a un tiempo distinto en el que pudieran abrirse nuevas posibilidades de un más amplio acceso de la población nacional al consumo de mercancías.

En parte, este cambio es el resultado de un lento pero sostenido crecimiento del mercado interno, provocado por una mayor organización de la economía en torno a productos líderes de exportación, como el café, y de algunas mercancías producto de la industrialización, en sectores como los textiles, el calzado, los alimentos, la construcción y los servicios.

De ahí que, a partir de la década de los años treinta, los temas fueran bastante variados que, por lo general, aludían a situaciones o preocupaciones en las que se viera involucrado el consumidor del producto. En estos anuncios, la modernidad era recurrente y se expresaba a través de ideas y observaciones sobre la aceleración del tiempo y sus efectos sobre el trabajo y la vida cotidiana de las personas; la ampliación del espacio vital, que dejaba de ser exclusivamente un espacio local, para hacer referencia también a un espacio universal al que frecuentemente se evocaba como el lugar de origen de los productos que se promocionaban o como un lugar que era posible visitar; la redefinición de los papeles de la mujer a partir de su incursión en el mundo del trabajo, de los deportes y en el de los negocios; la enfermedad, la salud y la belleza como estados que pueden ser controlados con la intervención de la ciencia; las tecnologías como recursos al servicio de la voluntad, entre otros.

\section{Los personajes del anuncio}

Los personajes de los anuncios publicitarios eran, fundamentalmente, hombres y mujeres adultos, de estrato social alto, elegantemente vestidos, que habitaban ambientes distinguidos, como una sala o una habitación espléndidamente decoradas, los salones de los clubes y los restaurantes elegantes, o desplazándose en automóviles de uso exclusivo.

Los individuos de una condición social distinta a la de la clase alta también eran representados 
elegantemente vestidos, habitantes de estos espacios, pero siempre puestos al servicio de la clase social alta, es decir, en calidad de meseros, empleadas de servicio y obreros o jornaleros conformes con su labor. Estos personajes, generalmente, representan al nuevo consumidor de las clases medias y bajas a través de su apariencia física, su estilo de vida, su condición social y sus maneras de actuar.

Dentro de las situaciones expuestas en los anuncios, la tendencia más representativa muestra que, para ilustrar la pertenencia de los personajes a las clases sociales, se recurre a provocar en el consumidor la reflexión sobre las situaciones expuestas. El otro recurso mediante el cual se hacen evidentes las clases sociales es haciendo referencia literal a las situaciones cotidianas y al papel que en ellas cumplen los personajes.

Las relaciones entre estos personajes de distintas clases sociales pueden ser definidas dentro del relato publicitario de los años treinta como armoniosas y hasta respetuosas, lo cual contradecía abiertamente en Colombia el contexto de ebullición social y política de los sectores populares en busca de la reivindicación de sus derechos y las resistencias de algunos sectores de la élite frente las reformas que proponían los gobiernos de la República Liberal. Sin embargo, esta manera de contar el relato publicitario no se traduce en su anacronismo, sino más bien en el propósito de dirigirse a una sociedad impactada por la masificación, lo cual exigía un relato interclasista, en el que los conflictos y las críticas no siempre tenían cabida.

Las actitudes de los personajes frente al contexto espacial eran mayoritariamente de conformidad con lo extranjero; esto se puede explicar no solo en virtud de la procedencia de los productos, sino, sobre todo, debido a su carácter moderno. Asimismo, esta conformidad también se observaba con lo nacional al mostrarse avanzando hacia una modernidad universal que estaba en vías de construcción. De ahí que se produjera una exaltación de lo nacional cuando se anuncia un producto elaborado dentro de las fronteras colombianas.

Las actitudes de los personajes frente al contexto temporal eran, fundamentalmente, de complacencia con el presente; esto obedece a que el relato publicitario tenía como propósito ofrecer en el consumo una respuesta inmediata a necesidades que eran propias de la modernidad. Las otras 
actitudes de los personajes que son significativas para considerar el contexto temporal eran las de resistencia y optimismo frente al futuro; esto se explica a causa de las incertidumbres que la modernidad generaba.

\section{Los productos anunciados y sus bondades modernas}

Los productos anunciados como modernos estaban llenos de bondades, que en los copys se hacían ver como la solución a algunos problemas y dificultades que traía consigo el estilo de vida moderno. De ahí que la publicidad construyera atributos para los diversos productos que promocionaba de manera positiva y siempre evitando los puntos de vista críticos.

No en otro sentido se entiende que los medicamentos, por ejemplo, fueran definidos como confiables, seguros, de acción rápida, efectiva, sin efectos secundarios, vigorizantes, purificantes de la sangre, garantizados, de alta calidad, profilácticos, sintéticos, confiables, frutos de la perseverancia de los químicos, que evitan el dolor y el sufrimiento, que ayudarán a vencer los obstáculos de la vida moderna, que estaban recomendados por los especialistas y que eran el resultado de los avances científicos.
Los productos del cuidado personal, por su parte, se anunciaban como higiénicos, desechables, limpiadores, blanqueadores, protectores, embellecedores, eran fáciles de aplicar, agradables, elegantes, placenteros, irresistibles, mejoraban la calidad de vida, se asociaban al buen vivir, rejuvenecían, producían resultados inmediatos y ayudaban a gozar de la vida plenamente.

Los alimentos eran, según los anuncios publicitarios, fáciles y rápidos de preparar, frutos de largas investigaciones y estudios de nutrición, eran nutritivos, higiénicos, balanceados, variados, saludables, deliciosos, estimulantes del apetito y del crecimiento, de fácil digestión, rápida asimilación y recomendados por los médicos.

A su vez, los electrodomésticos eran prácticos, livianos, funcionales, novedosos, revolucionarios, durables, portátiles, garantizados, ahorradores de energía, de esfuerzo, frutos de los últimos avances tecnológicos, mejoraban la calidad de vida, eran rápidos, seguros, eficaces, bellos y cómodos de usar.

Los servicios eran seguros, previsivos, cómodos, rápidos, revolucionarios, producían ahorro, tranquilidad, descanso, recreación, poseían alta calidad, permitían 
superar la ignorancia y la inexperiencia, estaban al alcance de todos, se prestaban a larga distancia, y evitaban que el consumidor tuviera que salir de casa.

Las prendas de vestir eran cómodas, elegantes, de moda, variadas, importadas, nacionales, bellas, durables, de alta calidad, para todos los gustos y todas las ocasiones, producían distinción, pero estaban al alcance de todos los bolsillos.

\section{La referenciación de los procesos de modernización}

Los procesos de modernización más referenciados fueron el bienestar individual y el avance científico y tecnológico, especialmente, el destinado al desarrollo de medicamentos y aparatos que mejoraban la calidad de vida de las personas y que dejaban en evidencia que esta no dependía, fundamentalmente, de los designios divinos, sino, sobre todo, de la voluntad individual.

La referenciación de estos procesos servía para suministrar legitimidad a los productos anunciados, pero también a los mismos procesos de modernización, ya que los relatos publicitarios se sustentaban a partir de argumentos que planteaban la cientificidad de los procedimientos mediante los cuales habían sido elaborados los productos. De ahí que fuera recurrente afirmar en los anuncios que los productos fueron "científicamente elaborados", "clínicamente comprobados", "médicamente recomendados" o, simplemente, "mundialmente aceptados".

En específico, el bienestar individual se representa asociado con el placer, la salud y la belleza adquiridas o producidas por el consumo de mercancías; el ahorro del esfuerzo, del tiempo y del dinero; la comodidad, el descanso y la recreación, pero también a través de la anticipación del riesgo, la inseguridad y el control de la contingencia; el acceso a la moda, a la novedad y al espacio mundo.

Aunados a estos procesos, se encuentra el desarrollo del transporte, con el anuncio de la construcción de carreteras, la venta de automóviles, así como de productos asociados a ellos (lubricantes, llantas) y de servicios de viajes terrestres, aéreos y fluviales que hacía más corto, cómodo y barato los desplazamientos de mercancías y pasajeros.

A su vez, otro capítulo importante en esta identificación de los procesos de modernidad lo ocupa el crecimiento del comercio a través del aumento de la producción 
nacional y de una mayor importación de mercancías, generada, fundamentalmente, por la más amplia disponibilidad de divisas que el lento crecimiento de las exportaciones había hecho posible.

\section{Las nociones de espacio moderno}

En los anuncios se distinguen tres tipos de espacios que, para efectos de esta investigación, se denominan como espacios domésticos o locales, espacios nacionales y espacios universales. Sin embargo, en un alto porcentaje de anuncios se encuentra que se presenta una profunda ambigüedad que no permite distinguir a qué tipo de espacios hacen referencia.

Cuando se habla de espacios domésticos o locales, se hace referencia a aquellos que escenifican o representan espacios exteriores, como las calles, y espacios interiores, como los de una casa, un restaurante, un club, una oficina, una fábrica o un almacén equipados con una variedad de muebles y equipos de los que se dice que mejoran la calidad de vida en cuanto la hacen más cómoda y fácil. En ellos, por lo general, ocurre una acción que involucra a personajes cuyos papeles se identifican en función de la ilustración de esos espacios; por ejemplo, la mujer que está en una cocina representa a la ama de casa, o el hombre que mueve una máquina en un taller es un técnico, etcétera.

A su vez, se habla de un espacio nacional cuando en el anuncio se hace explícito que el lugar de origen o de distribución del producto es Colombia, que las escenas ilustradas se corresponden con los espacios y monumentos característicos de sus ciudades o regiones o cuando se representa a Colombia a través del mapa, o cuando se hace uso de un personaje representativo de la historia del país.

$\mathrm{Al}$ espacio nacional se le identifica con el progreso en la medida en que se llevan a cabo en él procesos de gran alcance, como el crecimiento de la industrialización, el comercio, el transporte, la urbanización, la escolarización, que persigue siempre el propósito de alcanzar el bienestar y la prosperidad de quienes habitan este territorio.

Lo nacional es, entonces, un espacio en vías de transformación y redefinición que necesita del apoyo de los colombianos. Con ese planteamiento, se legitima la promoción de unos productos elaborados dentro del país que, según lo plantean 
los anuncios publicitarios, son capaces de competir con los que se importan haciendo, en esa medida, válido incentivar su consumo de manera permanente.

$\mathrm{Al}$ espacio universal se le distingue por la ilustración de símbolos característicos de países de donde procedían las mercancías anunciadas, o cuando se les identifica a estos con personajes, como actores, políticos, científicos o agentes de su historia. Asimismo, lo universal se identifica por la representación de ese país en el mapa, o por la declaración explícita en el copy del lugar de origen y del lugar donde se reconoce al producto.

Los productos de origen universal son aceptados en la medida en que han sido producidos en ámbitos donde el desarrollo, más que una promesa, es una realidad. De ahí que lo que el consumo de productos extranjeros permite es ponerse a tono con la modernidad que tiene lugar en esos países.

\section{Las nociones de tiempo moderno}

En la muestra de anuncios recolectados, se encontró que las piezas publicitarias daban cuenta de la transición del tiempo de la tradición al tiempo de la modernidad.
Esta transición se expresaba en la referencia explícita, en el copy y en las ilustraciones de algunas marcas, como Gillette, Bayer, Elna, Taxis Rojos, etcétera, que daban una explicación de cómo se llevaba a cabo la afeitada; cómo se curaban algunas enfermedades; cómo se empleaban máquinas de coser modernas, y cómo se prestaban los servicios de transportes antes y después, ayer y hoy, en el tiempo tradicional y en el tiempo moderno.

El tiempo moderno era entendido en los anuncios como el tiempo del progreso; era un tiempo producido a voluntad de los hombres, resultado de un conjunto de procesos que habían llevado a la humanidad a la máxima expresión de su desarrollo en lo científico, cultural y económico.

La temporalidad moderna era vista como una temporalidad de autorrenovación permanente; por eso, en los anuncios cobraban gran importancia las referencias a la novedad, a la actualidad, al cambio, a la moda, a lo que no permanecía estable, a lo que se alteraba, a lo que se transformaba y evolucionaba para mejorar. Ello explicaba el modo cómo se justifica la invitación permanente al consumo de productos 
que, aunque pueden nombrarse iguales, incluso si corresponden a la misma marca, para la publicidad son distintos y merecen ser comprados y consumidos.

En los anuncios, el tiempo moderno era un tiempo acelerado, por la cantidad y variedad de acontecimientos que en él tenían lugar. La consecuencia de esto era la generación del nerviosismo, del cansancio, la irritabilidad y las neuralgias, que si bien era cierto producían molestias, tenían la cura garantizada gracias a los avances de la ciencia y la tecnologías modernas que habían entregado a la humanidad el fruto de su trabajo y su esfuerzo, a través de los productos, como los de Squibb, que la publicidad promociona con orgullo a los consumidores.

Sin embargo, había en los tiempos modernos un componente de incertidumbre que se manifestaba en la imposibilidad de controlar plenamente el presente y el futuro; de hecho, en los tiempo modernos un elemento importante era la contingencia, que exigía estar preparados aun para lo inesperado, lo incierto. Una muestra de esto la proporcionaba la publicidad de seguros de vida y de los servicios bancarios, que invitaba a los consumidores a ser permanentemente previsivos, a tener planes, a proyectar el futuro con los ahorros para la vejez o la vida adulta de los hijos. Se trata, sin duda alguna, de una situación en la que no se podía estar confiado, en la que había que actuar y decidir a todo momento porque no había nada asegurado ni plenamente estable, por lo tanto, toda situación presente era desafiada por una eventualidad futura.

\section{Dimensión connotativa}

El análisis de la dimensión connotativa de los anuncios permitió explorar el significado que era sugerido a partir de la lógica de estructuración del contenido y de la vinculación con los contextos habitados por los destinatarios de anuncios publicitarios. De ahí que a este nivel se buscara comprender qué había tras la definición moderna de los productos, de la oferta de bienestar de los anuncios, de las ambigüedades o contradicciones del relato y de la persistencia de la tradición.

\section{La definición moderna e iluminista de los productos}

En los anuncios, se hacía evidente un permanente esfuerzo por definir a los productos que promocionaban 
como modernos, aunque estos hayan sido usados mucho antes de que pudiera hablarse de modernidad. De hecho, lo que permitía definirlos de esa manera consistía, fundamentalmente, en la atribución de propiedades que, más que a un producto, se asociaban a una marca, que se declara como partícipe del espíritu de un nuevo tiempo, de una nueva época.

Por este camino, la tarea de anunciar productos marcados y etiquetados se encuadraba dentro de aquel propósito general de la modernidad que consistía en revelar el mundo a través de la iluminación de la razón. En este sentido, lo que en términos generales parecían hacer los anuncios publicitarios era desplegar luces sobre los productos o sobre los problemas que ellos solucionaban, según lo planteado en los copys y hasta en las mismas etiquetas.

No en otro sentido puede entenderse que publicistas y anunciantes empezaran a exponer en su publicidad, en las etiquetas y en los envases de los productos, la composición de, por ejemplo, los medicamentos o los alimentos procesados, junto con las observaciones sobre los problemas que solucionaban o prevenían. Específicamente, en los anuncios publicitarios era recurrente el argumento de que los productos promocionados eran el resultado de años de estudio y experimentación científica y tecnológica, que el fabricante había llevado a cabo con el propósito de hacer posible el bienestar de la humanidad.

De acuerdo con esto, era claro que ya no se trataba de medicinas basadas en las fórmulas mágicas de las abuelas, pues, en adelante, anunciantes y publicistas se encargarían de recordarles a los consumidores que la inversión en ciencia y tecnología que el fabricante de medicamentos y alimentos procesados había hecho tenían un costo al que había que estar dispuesto a pagar si se quería disfrutar de la salud, a la que no de manera despreciable estaba ligado el bienestar que era, probablemente, la aspiración individual y colectiva más importante de los tiempos modernos.

No obstante, la iluminación que los anuncios provocaban sobre el mundo no se agotaba en estos asuntos; de hecho, en la relación que en el copy se establecía entre el consumidor y el producto se observaba que había una invitación a confrontar el destino, férreo principio de la 
tradición que implicaba la resignación ante lo que se creía irremediable porque desbordaba el parecer individual, con la voluntad, eje central de la autonomía y de la individualidad que definen el carácter moderno.

Una muestra de esto puede observarse en un tipo de anuncio que invitaba a consumir medicamentos para ejercer un control sobre la enfermedad, que en otro tiempo era vista como el producto del destino o de los designios divinos, ya fuera para curarla, haciéndola desaparecer por completo o para prevenirla, evitando que saliera a flote y acabara con la tranquilidad de la persona.

En el fondo, lo que la publicidad estaba sacando a flote era que se precisaba de un control, de un dominio de sí para poder tomar las riendas de la propia vida y poder conducirla por el sendero del bienestar y la felicidad. Por esto, ni la anemia ni el dolor de cabeza, de muelas o de estómago, podían seguir haciendo la vida de un hombre inútil o infeliz, menos cuando a su disposición se encontraban los medios con los que esos impedimentos u obstáculos podían desaparecer.

De hecho, lo que planteaban implícitamente los anuncios era que la resignación ante la enfermedad debía quedar atrás. Los malestares y las enfermedades no podían impedir el desempeño ni el rendimiento de un hombre que debía mantenerse saludable para poder dar muestras de autocontrol, lograr el bienestar propio, el de su familia y el de sus negocios.

No obstante, los anuncios publicitarios también daban el campanazo de alerta con respecto a las incertidumbres, los riesgos y las inseguridades que los nuevos tiempos de la modernidad traían consigo y, por eso, a las enfermedades no solo había que darles un tratamiento curativo, sino también preventivo, lo cual se reafirma en el llamado de atención que la publicidad hacía en los anuncios de algunos servicios, como los seguros de Colseguros, o los títulos de ahorros Bolívar y, en general, los servicios bancarios, como los del Banco Central Hipotecario o el Banco de Bogotá.

Un poco de lo que se trataba en estos casos era ver que si la modernidad comportaba incertidumbres, riesgos e inseguridades, también estaba en condiciones de producir los recursos y las condiciones que hacían posible el despliegue de algunas seguridades, como si se tratara de un mínimo de garantías. 
De este modo, aunque la desaparición o la muerte del padre de familia fuera siempre un riesgo que amenazara la seguridad y el bienestar familiar, existían empresas que anunciaban sus servicios de aseguramiento para que la familia no quedara desamparada si esto sucedía. Asimismo, aunque el robo o la pérdida de dinero fuera siempre un riesgo y que sus efectos produjeran incertidumbres en el futuro de la víctima, lo cierto es que tal como la publicidad anunciaba a los servicios bancarios, estos riesgos podían reducirse si el dinero era confiado a estas instituciones.

En últimas, a lo que el relato publicitario invitaba era a ejercer un control sobre la contingencia, sobre la enfermedad, el riesgo y la inseguridad que estaban siempre presentes en cualquier empresa nueva o en cualquier acción que se desplegara de manera novedosa y que, por lo tanto, implicara el desconocimiento de sus consecuencias.

En estas circunstancias, la publicidad generaba una conciencia de que las posibilidades del control estaban al alcance de cualquier mano si se disponía de los medios y del conocimiento suficiente. Debía ser por esta razón que en los anuncios publicitarios ni siquiera el tiempo escapaba a ese control. Esto es algo que podía verse en las observaciones que se hacían en los anuncios de cosméticos, como la crema Ponds o los productos de Elizabeth Arden, y en medicamentos, como el reconstituyente Cardui, especialmente elaborados para controlar el paso del tiempo en la piel y el cuerpo de una mujer, que en tiempos modernos buscaba preservar la juventud y la belleza como un valioso tesoro.

Adicionalmente, el tiempo era controlado porque, según lo sostenían los anuncios de cámaras y rollos fotográficos Kodak, podía ser detenido o congelado para mantener vivos y fieles los recuerdos de la infancia, en la vida adulta, a través de las fotografías que debían conservar los modernos álbumes familiares.

\section{La ideología bienestar en el centro de los procesos de modernización}

Es innegable que en el intento por promocionar mercancías que se definían como modernas, se llevaba a cabo también un proceso de legitimación del contexto en el cual esas mercancías se hacían consumibles. De ahí que deba afirmarse que, en ese proceso, la publicidad instituía 
una ideología mediante la cual no solamente invitaba al consumo de los productos, sino también a la aceptación de los procesos que giraban en torno a ellos.

Un buen ejemplo de esto lo constituye la relación imaginaria que esa ideología establecía entre la constitución de las redes eléctricas y el uso de electrodomésticos de distintas marcas, como los de la General Electric, o la relación que se establecía entre las industrias que, como Coltejer, fabricaban telas y a la vez producían el bienestar a sus trabajadores, pero también a sus consumidores, reafirmando con esto que en el relato publicitario, más allá de la finalidad comercial, estaba el propósito de generar conformidad con las transformaciones que se daban no solo en torno a la acumulación de capital, sino también en torno a lo que podemos denominar como una sensibilidad de la época, una sensibilidad moderna. Se trataba, en todo caso, de una sensibilidad que se definía por oposición a la que había caracterizado a una tradición, que había convertido en auténticos valores al sufrimiento, al esfuerzo, al trabajo y a la estabilidad, sin importar qué tan paralizante pudiera resultar esta.
En oposición a esto, la sensibilidad moderna, aunque no invalidaba abiertamente a la tradición que hasta entonces había sido dominante, apuntaba, al mismo tiempo, a otras direcciones, como la del trabajo, pero con mínimo esfuerzo, la del bienestar, la del consumo, la del entretenimiento, la de la promesa de la felicidad aquí y ahora, la de la comodidad, la belleza, la abundancia, la disponibilidad inmediata y un largo etcétera.

La promesa del bienestar como trasfondo ideológico del relato publicitario se manifestaba en la medida en que era sinónimo de la salud que prodigaban los medicamentos científicamente producidos, en el ahorro de tiempo y esfuerzo que era posible mediante el empleo de las permanentes innovaciones tecnológicas producidas sobre las máquinas que se empleaban en la industria y en el hogar; en el entretenimiento que brindaban los medios de comunicación y que llenaba el tiempo libre de una buena parte de la sociedad; en la velocidad, facilidad y comodidad con la que se llevaban a cabo algunas tareas que se realizan gracias a agentes especialmente dedicados a la prestación de servicios.

Dehecho, apartedel medicamento, la publicidad vendía la felicidad 
que prodiga el gozar de buena salud; además de la lavadora, la economía de esfuerzo; con la revista de modas o el programa de radio, una manera de estar al día con los acontecimientos o con el automóvil, la distinción, en fin, lo que se puede llamar hoy los estilos de vida, que independientemente de que sean distintos, le apuestan siempre a lo mismo: al bienestar.

\section{Las ambigijedades y contradicciones del relato publicitario}

Las ambigüedades y contradicciones del relato publicitario se expresaban, fundamentalmente, en la vacilación en el momento de valorar la tradición y la modernidad, ya que no es difícil encontrar anuncios que, al mismo tiempo que apelaban a la ciencia, también reivindicaran la importancia de fe o de la religión al resolver un problema o de enfrentar una situación o un desafío. Probablemente, las ambigüedades y contradicciones del relato suministren las pruebas para explicar no solo la resistencia de la tradición a ser superada, sino también el lento y tortuoso camino en el desarrollo hacia unas mentalidades modernas.

Otra vía por donde se expresan las ambigüedades y contradicciones del relato publicitario puede constatarse en algunos mensajes trabajados desde el punto de vista del copy y de otros desplegados en unas imágenes que no complementan ni reafirman el texto, sino que lo contradicen.

Asimismo, en el interior del relato se observan algunas situaciones en los que la posición de clase no es identificable porque al examinar los papeles se observa cómo las empleadas del servicio dan consejos a sus patronas y hasta pueden vestirse casi de manera similar a ella, como si estuvieran en un plano de igualdad social.

\section{La persistencia de la tradición}

A pesar de la radical oposición entre tradición y modernidad, el análisis de los anuncios publicitarios de la muestra no permite declarar una abierta hostilidad en contra de la tradición y de lo que ella representaba, debido a que, como ya se mencionó, era el contexto desde el que se proponía a los consumidores un cambio hacia la modernidad, pero también el único marco de referencia cognitivo, desde el que anunciantes y publicistas podían dirigirse a los consumidores, quienes muy probablemente no estarían 
dispuestos a abandonar sus costumbres y sus creencias para adoptar los nuevos estilos de vida propuestos en los relatos de la publicidad.

En este sentido, es muy posible que la manera más práctica de establecer puentes o sintonías con los consumidores fuera la de mantener en el nivel denotativo las referencias a la tradición, básicamente, con el propósito de hacer que las situaciones y personajes referenciados por el mensaje publicitario fueran conocidas o familiares a los consumidores. Seguramente de lo que se trataba era de evitar los ruidos, las disonancias o las resistencias que se pudieran interponer entre los propósitos publicitarios y dichos consumidores.

No obstante y más allá de lo que pueda suponerse como explicación de los propósitos que, de ese modo, motivaban a la estructuración del nivel denotativo de los mensajes, una cosa distinta es la que se puede observar en el análisis de la estructuración del nivel connotativo, de las representaciones que de esa tradición se hacía en dichos anuncios, donde pueden verse calificativos marcados con una carga evidentemente negativa, desde la que se descalificaba los modos de hacer, de pensar y de pensarse dentro de la tradición.
De esta manera, no es extraño que en los anuncios se sugiera que la tradición es una época de limitaciones y restricciones, donde se imponían límites a la búsqueda del placer y donde la única felicidad a la que había que aspirar era a la que se proponía en el discurso religioso, después de la muerte, legitimando así las privaciones y sufrimientos que eran propios de la vida terrenal, en el contexto de la tradición.

La otra marca estigmatizante de la tradición, construida en el nivel connotativo de los mensajes publicitarios, era la de su representación como un tiempo en el que había que resignarse ante las disposiciones del destino y, por eso, a la tradición se le entendía, en dichos anuncios, como una época donde el paso del tiempo y sus estragos sobre el cuerpo, ya fuera porque se envejecía o se enfermara, el esfuerzo físico, la dureza del trabajo, el encerramiento de la mujer en la casa, el peso de la responsabilidad de la familia sobre los hombros del hombre, los abismos sociales, etcétera, se aceptan como inevitables.

También a ese nivel se entendía a la tradición como una época donde la precariedad y la ineficiencia de los recursos científicos 
y tecnológicos eran aceptadas con resignación, aunque hicieran más vulnerables a las personas a causa de la enfermedad física o mental, el trabajo agotador, la incomodidad, la superstición, el miedo y la pobreza. Asimismo, las creencias ligadas a la tradición eran calificadas como irracionales, sin fundamento, anacrónicas, elementales, autoritarias y arbitrarias, en todo caso tendientes o proclives a limitar o restringir la libertad del individuo.

Probablemente, uno de los pocos atributos reconocible en los anuncios publicitarios, que en el análisis connotativo permita el rescate de la tradición, es la valoración de la experiencia, pues, dentro de los anuncios publicitarios se atribuía más aceptación de los consumidores de todo el mundo a aquellos productos que tenían como respaldo la experiencia de sus fabricantes. En este sentido, la experiencia del fabricante se convertía en un sinónimo de calidad y en una garantía para el consumidor que podía encontrar el ofrecimiento de la compra más legítimo si conocía qué tanto y quién había producido el producto.

\section{A manera de conclusión: la modernidad contada por la publicidad en Colombia}

En Colombia, como probablemente ocurre en el resto de América Latina, el proceso de modernidad no recorre de manera simultánea la geografía nacional. Esto se explica debido a que fue en las ciudades y en los grandes pueblos donde primero llegaron y se instalaron no solo los procesos de modernización, sino también las primeras imágenes de la modernidad que circularon en los periódicos y en las salas de cine.

El papel de la publicidad en la inserción de dichas imágenes resultó ser definitivo, primero, en la imaginación de la élite que podía comprar y leer el periódico y más adelante en la de un grupo más amplio que tenía acceso al consumo de bienes y servicios.

Las imágenes modernas de la publicidad en Colombia, aunque muchas de ellas importadas, abrían y ampliaban un mundo de posibilidades nuevas que, además de facilitar la vida, estaban revelando a las personas unas maneras distintas de pensar, actuar, de divertirse y de aspirar a la felicidad aquí y ahora.

El mundo revelado por los anuncios de la publicidad era un 
mundo luminoso, bello, cómodo, feliz y al alcance de todos. Era un mundo que no estaba dado, sino que había que construir, pero no de cualquier manera, pues, los resultados deseados solo se conseguían con el empleo de la ciencia y la tecnología y, desde luego, con el abandono de los mandatos de la fe y la tradición. De ahí que la emergencia del relato publicitario de la modernidad suponga un desafío no solo para las imágenes tradicionales del mundo, sino también para todo lo que este era o representaba.

En los anuncios, las exigencias prácticas de la vida moderna exigían la sustitución de la sumisión al destino por la voluntad de ejercer un control sobre el propio cuerpo y más específicamente sobre las enfermedades y la apariencia personal; sobre el espacio, que ahora podía redefinirse en función de las propias aspiraciones; sobre el tiempo, presente y futuro; sobre las responsabilidades, como el trabajo y las posibilidades de un mejor vivir a través del ascenso social; en suma, un control sobre lo que para la tradición era el destino gobernado por un designio divino y que ahora dependía, fundamentalmente, de la acción individual.
De este modo, el relato moderno de los anuncios publicitarios creaban la conciencia de que era posible habitar un mundo mejor, no solamente si se adquirían mercancías para el consumo, en el sentido de compre tal cosa y hágase rico, bello y feliz, sino también llevando a las personas a pensar que esa belle$\mathrm{za}$, felicidad y riqueza comportaban un costo que cada quien tenía que estar dispuesto a pagar.

Los anuncios publicitarios modernos reiteraban que no había nada dado o gratuito, ni siquiera un destino lleno de penurias y desgracias, que la posesión de riqueza, belleza y felicidad tenían como contraprestación la exigencia del esfuerzo que cada quien debía hacer si no quería correr el riesgo de quedarse rezagado ante las demandas de los nuevos tiempos.

No en vano las vías que el relato publicitario recorre para lograr estos propósitos resultan ser las que le proponen al consumidor una reflexión en la que la exigencia es que razone sobre los beneficios pero también sobre los costos de las mercancías que se le propone comprar. De ahí que en el copy no solo estén definidas las cualidades del producto, sino también los beneficios que 
esas mercancías otorgan a quienes las consuman.

De alguna manera, lo que el copy le dice al consumidor es que lo que él necesita es justo lo que el producto anunciado tiene para ofrecer, esto es, calidad, durabilidad, eficiencia, rapidez, confort o notoriedad. En el anuncio automóvil Nash, por ejemplo, se pueden conjugar la funcionalidad, la calidad y la belleza, para hacer que su poseedor se distinga; o en el anuncio del polvo de hornear Royal se pueden conjugar, al mismo tiempo, la facilidad y la eficiencia, para que su usuaria disponga de más tiempo; o también se pueden conjugar en el anuncio de la Compañía Colombiana de Gas, la limpieza, rapidez y economía, necesaria en cualquier hogar.

En todo caso, es gracias a esta conjugación de cualidades que el relato publicitario moderno logra indicar que la ciencia y la tecnología avanzaban para ponerse al servicio del individuo, que en su vida cotidiana necesitaba reducir el esfuerzo de desempeñarse activamente tanto en el trabajo como en el hogar.

Para el relato publicitario moderno era tanto como decir que la ciencia y la tecnología abandonaban ese aire de misterio que las había caracterizado por tanto tiempo, para estar presente en el día a día de las personas, ofreciendo soluciones integrales a problemas que no habían podido ser resueltos completamente durante la tradición, ya que sus productos, en general, los resolvían a medias, esto es, siendo funcionales, pero pesados y feos, o siendo bellos pero inútiles, o siendo necesarios, pero no siempre eficientes.

La ciencia y la tecnología serían, al decir del relato publicitario, las herramientas con las que se abrirían los caminos hacia la prosperidad y el progreso, porque gracias a ellas se fabricaban los productos que, como las llantas de Icollantas, recorrerían las carreteras nacionales para transportar la producción de la industria nacional o para llevar a cada rincón de nuestra geografía las mercancías que contenían el germen del progreso.

Asimismo, y según lo plantea también el relato de la publicidad, la organización moderna de la vida económica no solo producía productos y servicios que solucionaban problemas del diario vivir, sino también los que se pudieran presentar de manera inesperada, demandando, de esta forma, soluciones contingentes. Este es un caso 
claramente observable en la publicidad de seguros y títulos de ahorro, cuyo propósito es hacer reflexionar al consumidor sobre situaciones que no hacen parte de la cotidianidad del consumidor pero que no por ello no dejan de presentarse.

En este sentido, se puede afirmar que la modernidad es un tiempo en el que los problemas, además de ser solucionables, son previsibles $y$, en esa medida, controlables, incluso antes de que se manifiesten.

Debe aclararse que esto no puede llevar a pensar que la publicidad de 1900 a 1950, anunciada en Colombia, llevara solo a la creación de imágenes positivas en torno a la modernidad, porque de hecho la publicidad llamó siempre la atención no solo sobre los riesgos y las dificultades que el paso de la tradición a la modernidad comportaban, sino también sobre los problemas que eran constitutivos de la modernidad y que tenían como consecuencia fundamental la desaparición del estilo de vida tranquilo, sosegado, característico de la tradición.

En el polo opuesto, la publicidad pone al estilo de vida moderno, caracterizado por la artificialidad de la vida, la aceleración de su ritmo y las exigencias del mundo laboral. $\mathrm{La}$ primera, la artificialidad de la vida moderna, supone que esta está llena de nuevos artificios, materiales y simbólicos, que la hacen, aunque más cómoda, también más complicada y, por lo tanto, más impactante sobre los estados físicos y anímicos de las personas. De ahí que los anunciantes y publicistas sean los primeros en llamar la atención sobre los nuevos papeles y preocupaciones que caracterizan a los hombres y mujeres modernos.

La artificialidad de la vida se evidencia en la medida en que esos nuevos papeles y preocupaciones alteran de manera radical a la tradición, que, en este sentido, puede considerarse como un orden natural al que los nuevos tiempos vendrían a devastar, porque eran otras las circunstancias que hombres y mujeres debían vivir.

Por otra parte, la aceleración del ritmo de la vida moderna supone la existencia de un tiempo que transcurre más rápido, pero no sin producir sus efectos, algunas veces, nocivos para la salud y, por esto, la publicidad plantea a los medicamentos como recursos terapéuticos para curar algunas molestias que esa aceleración produce en la vida anímica de las personas. 
Pero más allá de las molestias sobre la vida anímica, la aceleración del tiempo exige más productividad, y ello quiere decir que el individuo debe adaptarse a ese ritmo si quiere alcanzar el éxito que en estas circunstancias se hace evidente en sus posibilidades de consumo, que, en últimas, se entienden como el acceso a una mayor calidad de vida y, por lo tanto, al bienestar y la felicidad.

Finalmente, las exigencias del mundo del trabajo, como rasgo característico del estilo de vida moderna, indica que la exigencia de una mayor cualificación laboral no era solo un problema de conocimientos, sino también el problema de moldear una actitud cuya orientación permitiera una mayor disciplina y un mayor rendimiento en la fábrica o en el lugar de trabajo.

De lo que se trataba, en últimas, era de producir en el trabajador una conciencia y un compromiso de cumplir cada vez más y mejor al empleador, de mantenerse atento a los cambios que se producían en el entorno científico y tecnológico del lugar de trabajo, para tratar de responder de la mejor manera a ellos.

Con respecto a la publicidad, lo que se evidencia es que los cambios, presentes en estos rasgos característicos de la modernidad, no fueron indiferentes para la industria publicitaria y que, por el contrario, fueron objeto de una tematización permanente, que alertaba a los consumidores sobre cómo ponerse a tono con esos cambios, con el objetivo, sobre todo, de lograr que el país, al fin, lograra ser moderno.

\section{Referencias}

Ballent, A. (1996). La publicidad de los ámbitos de la vida privada. Representaciones de la modernización del hogar en la prensa de los años cuarenta y cincuenta en México. $\mathrm{Al}$ teridades, 6(11), 53-74.

Brunner, J. J. (1993). América Latina en la encrucijada de la modernidad. Revista Foro, 20, 96.

Contursi, M. E. y Ferro, F. (2000). La narración. Usos y teorías. Bogotá: Norma.

Corredor, C. (2001). La modernización inconclusa. En Misas, G. Desarrollo económico y social en Colombia (pp. 15-37). Bogotá: Siglo XXUniversidad Nacional de Colombia. Cueto, J. (1987). La sociedad de consumo de masas. Barcelona: Salvat. 
Eguizábal Maza, R. (1998). Historia de la publicidad. Madrid: Eresma \& Celeste.

Freud, S. (1987). El malestar en la cultura. Madrid: Alianza.

Jimémez, M. F. (1996, enero-junio). En el festín de la civilización: los límites de la hegemonía de los hacendados a comienzos del siglo XX en Colombia. Innovar, 7.

Kalmanovitz, S. y López, E. (2002). Instituciones y desarrollo agrícola en Colombia a principios del siglo XX. Bogotá: Banco de la República.

Kalmanovitz, S. y López, E. (2003). Economía y nación. Historia económica de Colombia. Bogotá: Norma.

Londoño Vélez, S. (2002). El arte en la publicidad: Nacional de Chocolates 1920-1960. Medellín.

Mattelart, A. (2003). La publicidad en la era transnacional. En Geopolítica de la cultura. Bogotá: Ediciones Desde Abajo.

Pedraza, Z. En cuerpo y alma: visiones del progreso y de la felicidad. Bogotá: Corca editores.
Pérez Tornero, J. M. (1992). La seducción de la opulencia: publicidad, moda y consumo. Barcelona: Paidós.

Ramonet, I. (2002, abril). La fábrica de los deseos. En Le Monde diplomatique en español, pp. 22 y 23.

Reyes Trigos, C. (2003). Visión panorámica de los estudios sobre la narración. Revista de Humanidades: Tecnológico de Monterrey, 15, 95-119.

Simmel, G. (1986). Las grandes urbes y la vida del espíritu. En El individuo y la libertad. Barcelona: Editorial Península.

Téllez Bernal, H. (1981). Cincuenta años de la publicidad en Colombia. Bogotá: Editorial Gente Nueva.

Villadiego Prins, M. (2003a). Publicidad, comunicación y cultura. Claves para una comprensión cultural de la publicidad. La Tadeo, 68 .

Villadiego Prins, M. (2003b). Ganancias de la publicidad, pérdidas de la escuela: hacia dónde apunta la socialización de los relatos y prácticas dominantes en la sociedad contemporánea. Pedagogía y Saberes, 19, 75-84. 
Villadiego Prins, M.; Bernal, P. y década de 1930. Signo y PensamienUrbanczyk, M. (2006). Publicidad to, 49, 160-169. y modernidad en Colombia. Apuntes para una comprensión del relato publicitario de la modernidad en la Vovelle, M. (1985). Ideología y mentalidades. Barcelona: Ariel. 
- Narrativas publicitarias de la modernidad - Mirla Villadiego, Patricia Bernal \& María Urbanczyk
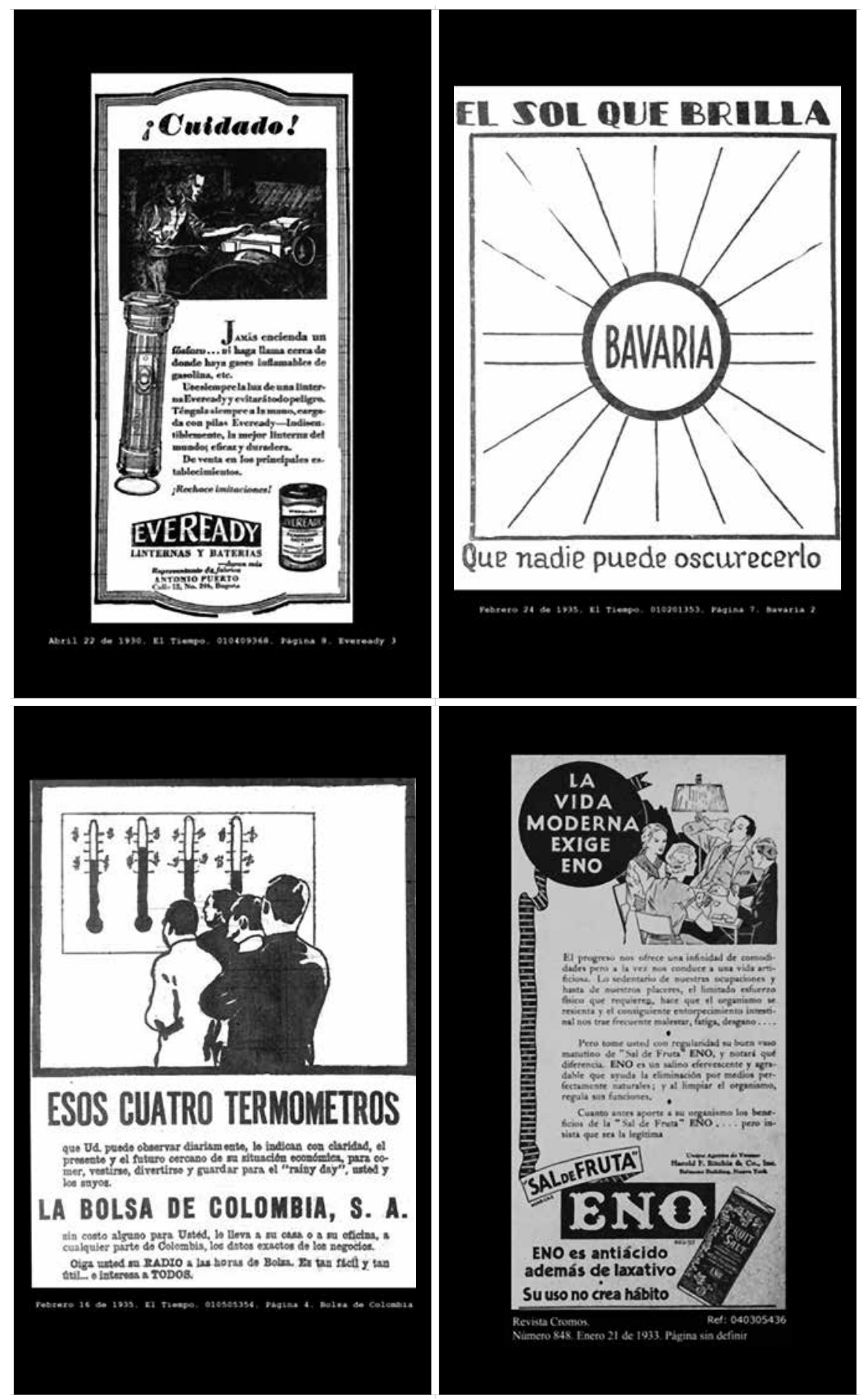

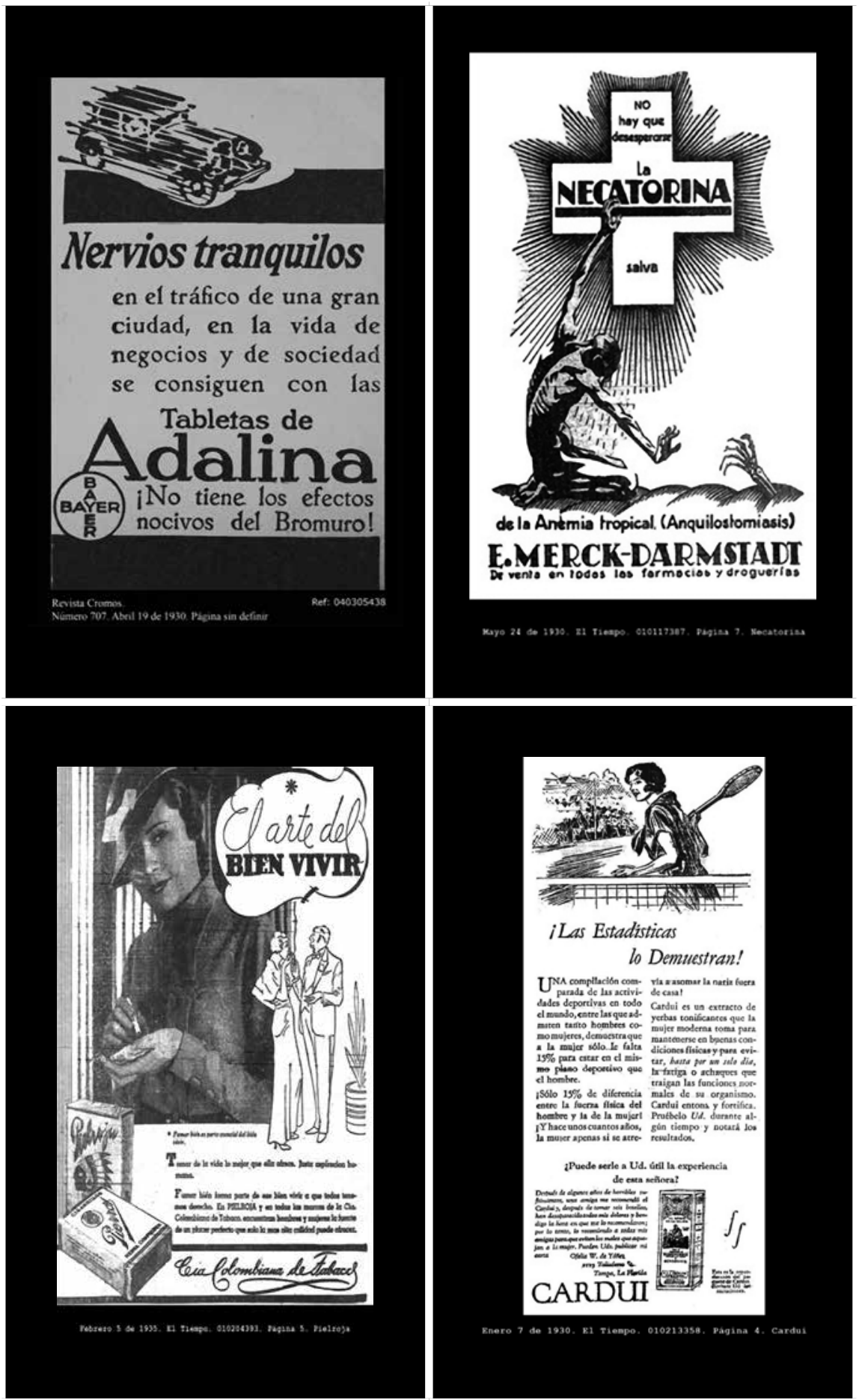
- Narrativas publicitarias de la modernidad - Mirla Villadiego, Patricia Bernal \& María Urbanczyk 